\title{
In-line tubular ion-exchanger to enhance selectivity in enzyme-based flow-injection potentiometry: application to determination of L-glutamine in bioreactor media
}

\author{
Sara A Rosario and Mark E Meyerhoff \\ Department of Chemustry, The Unversity of Michigan, Ann Arbor, MI 48109 (USA) \\ Marek Trojanowicz \\ Department of Chemustry, Unversuty of Warsaw, Warsaw (Poland)
}

(Received 1st October 1991)

\begin{abstract}
A new approach for reducing positive errors caused by endogenous cationic interferences when using ammonium ion-selective electrodes as detectors in immobilized enzyme-based flow-injection analysis systems is described The method involves the use of an in-line tubular cation-exchange unit ( $\mathrm{g}$, Nafion) placed between the injection valve and the downstream immobilized enzyme reactor/electrode detector portion of the system Interferent cation species within the sample slug are exchanged for other cations (replacement rons, e $\mathrm{g}, \mathrm{Li}^{+}$) contained within a reservoir solution surrounding the ion-exchange tubing The membrane electrode exhibits much less response toward the replacement cations, consequently, the detected concentration of ammonium ions generated downstream within the enzyme reactor is directly proportional to the level of analyte substrate present in the sample The influence of various experimental parameters on the efficiency of the in-line exchanger as well as the general advantages and limitations of this approach are examined The analytical utility of the concept is demonstrated by the rapid and accurate determination of $\mathrm{L}$-glutamine in bioreactor media via the use of immobilized glutaminase enzyme
\end{abstract}

Keywords Flow system, Ion exchange, Potentiometry, Ammonum electrode, Bioreactor media, Glutamune

There are a very large number of highly active enzymes that catalyze the conversion of selected biomolecules to ammonia / ammonium [1,2] Consequently, methods based on the use of immobılized forms of these enzymes in conjunction with transducers that can detect the liberated ammonia/ammonium species could have enormous bioanalytical utility Previous efforts in these laboratories [3-6] and elsewhere [7-12] have focused on examining approaches to reduce or eliminate positive errors caused by the presence of endogenous ammonia/ammonium (as well as other interferent cations present in biological samples) when using such immobilized enzymes in conjunction with flow-through potentiometric ammonium ion and ammonia gas sensing systems Techniques proposed recently have included the in-line removal $[3,4]$, exclusion [5], and consumption [7-10] of the endogenous interference via the use of gas-permeable tubes, anion-exchange membranes, or addition of enzymatic reagents (e.g , glutamate dehydrogenase) The present report describes an alternate solution to the interference problem through the use of an in-line cation-exchange tubing to remove endogenous interferent ions prior to the sample passing through the enzyme/electrode detector portion of a flow-injection arrangement 
The concept of using 1on-exchange to reduce background levels of ammonia/ammonium in samples is not completely new Indeed, Mascinı and Pallesch [12] as well as Meyerhoff and Rechnitz [13] used 1on-exchange resins to pretreat urıne and blood samples for subsequent enzymeelectrode measurements of creatinine Similarly, post-analytical column ion-exchange is the method of choice for reducing the background conductivity of the eluent in modern ion chromatography systems (e g, suppressed systems $[14,15])$ In replacement ion-chromatography, an approach pioneered by Hieftje and coworkers $[16,17]$, ions separated on a conventional suppressed 1on-exchange system are further exchanged quantitatively for more readily detected replacement ions within a third ion exchanger incorporated into the chromatographic system In these various chromatographic arrangements, suppressor and replacement stages of the systems can be classical ion-exchange columns, although newer 1onomer membrane-based exchangers, used either in flat or tubular form, offer attractive advantages Indeed, the tubular 1on-exchange fibers can be incorporated conveniently into flowing arrangements and maintained in their appropriate ion loaded state by bathing the tubing in a reservoir of suitable electrolyte For efficient cation exchange, varying lengths of narrow bore Nafion tubing have proved to be quite effective $[15,18]$

In this work, the feasibility of using Nafion tubing in-line to reduce endogenous cation interferences when employing enzymes that liberate ammonia/ammonium in conjunction with a flow-injection (FIA) system equipped with an ammonium ion electrode detector was examined As a model, the FIA arrangement was configured to determine L-glutamine in bioreactor media via the use of immobilized glutaminase This enzyme catalyzes the following reaction

L-glutamine $\rightarrow$ L-glutamate $+\mathrm{NH}_{4}^{+}$

As shown in Fig 1, injected samples containing glutamine flow first through a given length of Nafion tubing where endogenous ammonium ions as well as potassium and sodium are exchanged for lithium or tris(hydroxymethyl)ammonium ions

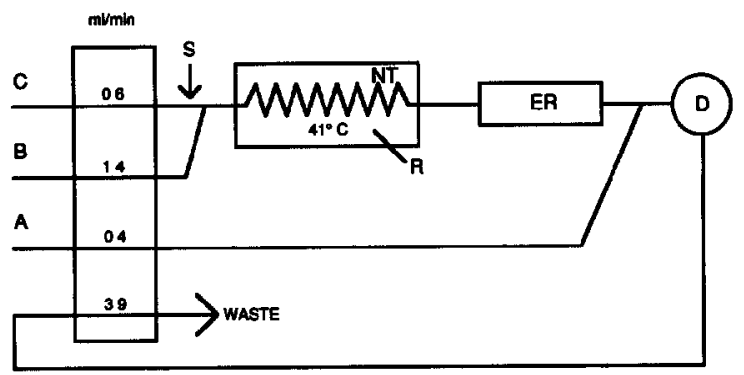

Fig 1 Schematic of FIA system used to measure L-glutamıne in bioreactor media $\mathrm{C}=$ water carner stream, $\mathrm{B}=$ diluent buffer stream, $A=002 \mathrm{M} \mathrm{NaCl}, S=$ sample injection valve, $\mathrm{R}=$ reservoir of buffer electrolyte, $\mathrm{NT}=$ Nafion tubing, $\mathbf{E R}$ $=$ immobilized glutaminase enzyme reactor, $\mathrm{D}=$ ammonium ion-selective electrode detector with SCE reference

Glutamıne, being present predominately as a zwitterion under the operating conditions of the system, does not permeate the walls of the Nafion tubing and is converted nearly quantitatively to ammonium ions within a downstream enzyme reactor containing immobilized glutaminase The ammonium cons are then detected potentiometrically via a nonactın-bascd ammonium sclective polymer membrane electrode with minimal interference from the original ammonium, potassium and sodium present in the injected sample The analytical utility of the proposed system is demonstrated by determining accurately the concentration of L-glutamıne in media samples from hybridoma bioreactors

\section{EXPERIMENTAL}

\section{Apparatus}

Figure 1 lllustrates the basic manifold arrangement used for L-glutamine measurements in bioreactor media Evaluation of the efficiency of the in-line ion-exchange system and the practical improvements in the selectivity were carried out with a very similar arrangement, except that the stream of $\mathrm{NaCl}$ solution (A) was elımınated The $\mathrm{NaCl}$ stream was added to the final system to help minimize electrical noise and drift, and to enhance baseline recovery In all cases, solution delivery was accomplished with a Rainin mult1channel peristaltic pump (Woburn, MA) A PTFE 
rotary injection valve (Rheodyne, Cotat1, CA) with a 20- $\mu$ l sample loop was used for sample and standard introduction The in-line cation exchanger was a coiled length of Nafion 811x tubing (0625 mm 1 d) obtained from Perma Pure products (Toms River, NJ) This tubing was bathed in etther a Tris acetate or lithium acetate buffer, $\mathrm{pH}$ 49

Flow-through potentiometric ammonium measurements were made with an ammonium ionselective electrode The electrode was prepared by incorporatıng nonactun into a plasticized (dıpentylphthalate)cellulose triacetate membrane (according to the method described previously [19]) and then mounting a piece of this membrane into a Phillips electrode body (ISE-561, Glasblasere1 Moller, Zurich) The electrode was fitted with a special cap for use as a flow-through detector in a large volume wall-jet configuration (see Ref 5) A saturated calomel reference electrode along with the working ammonium electrode (connected to the FIA system via a small length of narrow bore PTFE tubing) were placed in a large beaker of reagent buffer Potentiometnc response of the workıng electrode was measured with either an Altex (Model 4500) or an Accumet (Model 910) $\mathrm{pH} / \mathrm{mV}$ meter, and recorded on a Fisherall Series 5000 strip-chart recorder

The enzyme reactor consisted of a glass tube (7 $\mathrm{cm} \times 33 \mathrm{~mm} \mathrm{1d}$ ) packed with immobilized glutaminase on controlled pore glass beads The preparation of this enzyme reactor has been described previously [6]

\section{Reagents}

Cellulose triacetate (CTA) and nonactın were obtained from Fluka (Ronkonkoma, NY) and dipentylphthalate from Eastman Kodak (Rochester, NY) Glutamınase (EC 3512 ), grade V from Eschenchia coll, and Iscove's Modified Dulbecco's Medium (IMDM) were products of Sigma (St Louis, MO) All other chemicals were reagent grade Buffer solutions were prepared with distilled-deionized water

\section{Evaluation of cation removal effictency}

The effect of several experimental variables on the ability of the in-line ion exchanger to reduce the background levels of injected ammonium ions (at 1 and $4 \mathrm{mM}$ ) was examined in detal In general, these experıments were carried out by using the manifold shown in Fig 1 without the enzyme reactor and sodium chloride line (reagent A) in place Standards of ammonium chlonde (as well as sodium and potassium chlonde) were first injected into the system with a PTFE dummy coil (of same length and inner diameter as the Nafion tubing) in place of the cation-exchange unit to obtain calibration curves for the cations under the given operatıng conditions ( $1 \mathrm{e}$, same dispersion coefficient as with Nafion exchanger in place) Subsequently, the dummy coll was removed and standards were injected with the appropriate Nafion unit present Peak heights (n $\mathrm{mV}$ ) were compared to the prior calibration curve data to determine the \%removal efficiency of the in-line cation-exchange unit

\section{Measurements of L-glutamine in bioreactor me- dia}

L-Glutamine standards were prepared in fresh IMDM media and injected into the FIA system (with $300 \mathrm{~cm}$ Nafion tubing and glutaminase enzyme reactor in place) Peak heights (in $\mathrm{mV}$ ) were recorded and plotted vs the logarithm of $\mathrm{L}$ glutamine to obtain the standard curve Twentytwo hybridoma media samples were obtained from the Cell Culture Laboratory in the Department of Chemical Engineering at the University of Michigan These samples were injected directly into the proposed FIA system, and L-glutamine concentrations determined from the prior calıbration curve data L-Glutamine in these same samples was also determined by a standard liquid chromatography (LC) method [20]

\section{RESULTS AND DISCUSSION}

Initial efforts focused on determining the conditions required to obtain optımal in-line removal of sample ammonium ions Factors examined included the composition and concentration of the electrolyte solution bathing the Nafion tubing, the temperature of this electrolyte solution, the length of the Nafion tubing, as well as the total 
combined flow-rate of sample carrier (C) and buffer diluent (B) streams through the system (see Fig 1) Choice of the bathing electrolyte solution is dictated by the selectivity of the ammonium membrane electrode detector over the replacement cation of this electrolyte In addition, the $\mathrm{pH}$ of this electrolyte solution should correspond to the $\mathrm{pH}$ of the diluent buffer (line $\mathrm{B}$ in Fig 1) so as to maintain optimum $\mathrm{pH}$ cond1tions for the downstream enzymatic reaction In the case of the glutamine/glutaminase model system examined here, maximum enzyme activity occurs at pH 49 [21], and an acetate/acetic acid buffer was chosen to maintain this $\mathrm{pH}$ The cationic component of this buffer is the ion that will replace the endogenous ammonium and other interferent cations in the injected sample Since nonactin-based ammonium electrodes are known to exhibit high selectivity over lithium and tris(hydroxymethyl)ammonium [22] $\left(k_{\mathrm{NH}_{4} / \mathrm{Ll}}=10^{-5}\right.$, $k_{\mathrm{NH}_{4} / \text { Trs }}=10^{-5}$ ), these species were both used as the cationic component of the acetate buffers with nearly equal results In general, higher concentrations of the bathing electrolyte buffer were found to yield better ion-exchange efficiency and thus $05 \mathrm{M}$ lithium acetate/acetic acid or $05 \mathrm{M}$ Tris-acetate/acetıc acid, $\mathrm{pH} 49$, were employed in subsequent studies

Figures $2 \mathrm{~A}-\mathrm{C}$ summarize the effects of varying temperature, Nafion tubing length and total flow-rate on the efficiency of ammonium ion removal (for 1 and $4 \mathrm{mM} \mathrm{NH}{ }_{4} \mathrm{Cl}$ samples) using a lithium acetate/acetic acid buffer as the bathing electrolyte As expected, increasing the length of the Nafion tube or the temperature of the bathing electrolyte solution improves the efficiency of the ion-exchange process, while higher flow-rates lead to shorter residence times and poorer efficiencies in ammonium ion removal There are certain practical considerations that limit the extent that these parameters can be varied to achieve opt1mal ion exchange in a useful enzyme-based FIA system For example, temperatures greater than $45^{\circ} \mathrm{C}$ will certainly enhance cation removal efficiency, but such temperatures will also promote denaturation of the immobilized enzyme in the downstream reactor once it is incorporated into the system ( $1 \mathrm{e}$, the temperature of the carrier/ sample stream is raised during the long residence time in Nafion tubing) Extremely slow flow-rates
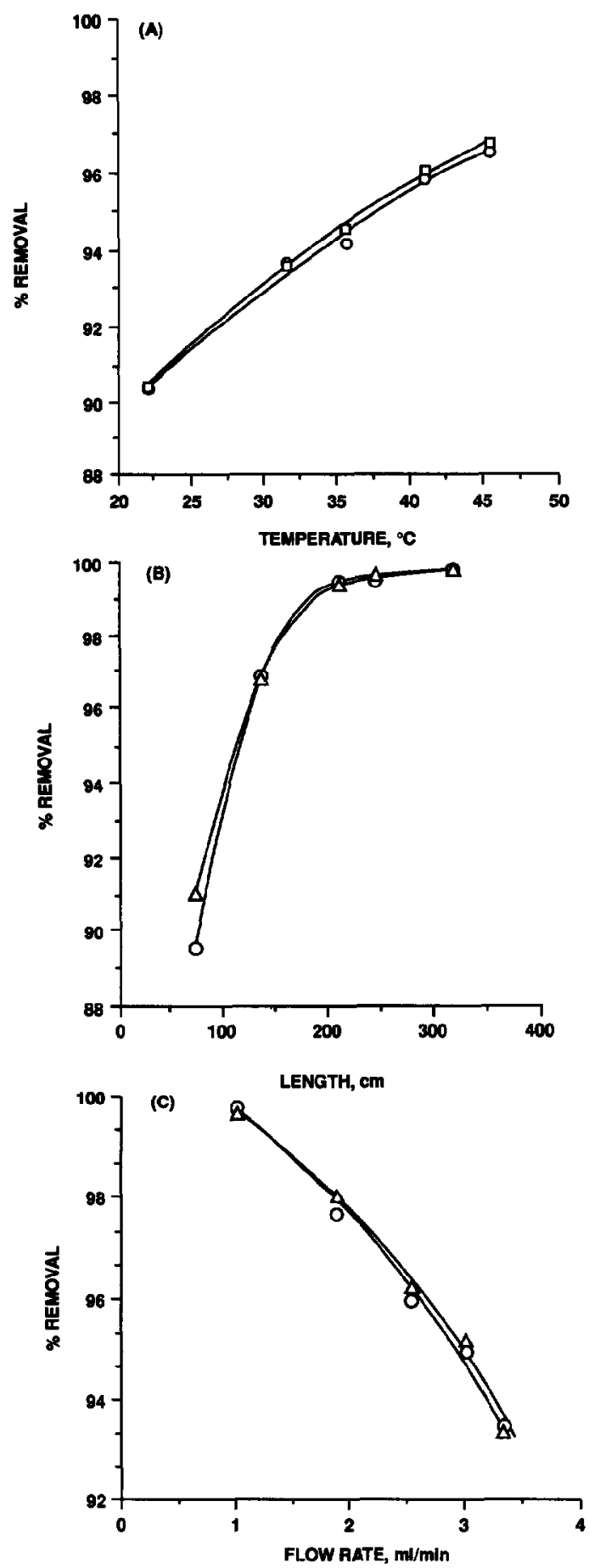

Fig 2 Effect of various parameters on the removal efficiency of injected $1(0)$ and 4 (口) $\mathrm{mM}$ ammonium standards using in-lıne Nafion ın-exchange tubıng (A) Effect of temperature tubing length $=135 \mathrm{~cm}$, total flow-rate $=254 \mathrm{ml} \mathrm{min}^{-1}$ (B) Effect of Nafion tubing length temperature $=41^{\circ} \mathrm{C}$, total flow-rate $=254 \mathrm{ml} \mathrm{min}^{-1}$ (C) Effect of total flow-rate of streams $\mathrm{C}+\mathrm{B}$ (see $\mathrm{Fig} 1$ ), temperature $=41^{\circ} \mathrm{C}$, tubing length $=135 \mathrm{~cm}$ 


\section{TABLE 1}

Summary of percent removal for interferent cations at different concentrations using in-line Nafion tubing in FIA system ${ }^{\mathrm{a}}$

\begin{tabular}{lrrr}
\hline $\begin{array}{l}\text { Cation } \\
\text { concentration } \\
\text { (mM) }\end{array}$ & \multicolumn{3}{l}{ Removal (\%) } \\
\cline { 2 - 4 } & $\mathrm{K}^{+}$ & $\mathrm{Na}^{+}$ & $\mathrm{NH}_{4}^{+}$ \\
\hline 01 & 1000 & 1000 & 1000 \\
03 & 1000 & 1000 & 989 \\
10 & 981 & 1000 & 996 \\
30 & 993 & 997 & 998 \\
10 & 997 & 971 & 998 \\
30 & 998 & 984 & 998 \\
\hline
\end{tabular}

$300 \mathrm{~cm}$ Nafion tubing at $41^{\circ} \mathrm{C}$ in $05 \mathrm{M}$ lithium acetate/acetıc acid buffer, $\mathrm{pH}_{49}{ }^{\mathrm{b}}$ Average of two determinatıons

and/or a very long Nafion tube will further and interferent ion removal, but at the expense of increasing system dispersion and decreasing sample throughput For these reasons, based on the data summarized in Fig $2 \mathrm{~A}-\mathrm{C}$, the following compromise conditions were chosen for further biosensing work $300 \mathrm{~cm}$ length of Nafion, total flow-rate $20 \mathrm{ml} \mathrm{min}^{-1}(\mathrm{C}+\mathrm{B}$ streams of Fig 1$)$, and temperature $=41^{\circ} \mathrm{C}$ Under these conditions, very high removal efficiencies were observed, not only for ammonium lons, but for potassium and sodium as well (see Table 1)

By integratıng the glutamınase enzyme reactor into the FIA manifold with the Nafion tubing unit in place, the system is capable of detecting L-glutamine with a greatly enhanced selectivity over the endogenous ammonum, potassium and sodium present in the injected sample This is shown clearly in Fig 3 which compares the potentiometric response of the system to injections of standard L-glutamine, $\mathrm{KCl}, \mathrm{NH}_{4} \mathrm{Cl}$, and $\mathrm{NaCl}$ without (A) and with (B) the Nafion tubing unit in-line Note that the data for $F_{1}$ g $3 A$ were generated by using an equivalent length / diameter PTFE dummy tube in place of the Nafion tubing unit Apparent selectivity coefficients for the two arrangements can be calculated using the fixed potential-separate solution method often employed for evaluating the selectivity of ion-selective electrodes (see Table 2) For ammonium and potassium, the two lons to which the membrane electrode detector $1 \mathrm{~s}$ most responsive [22], en-

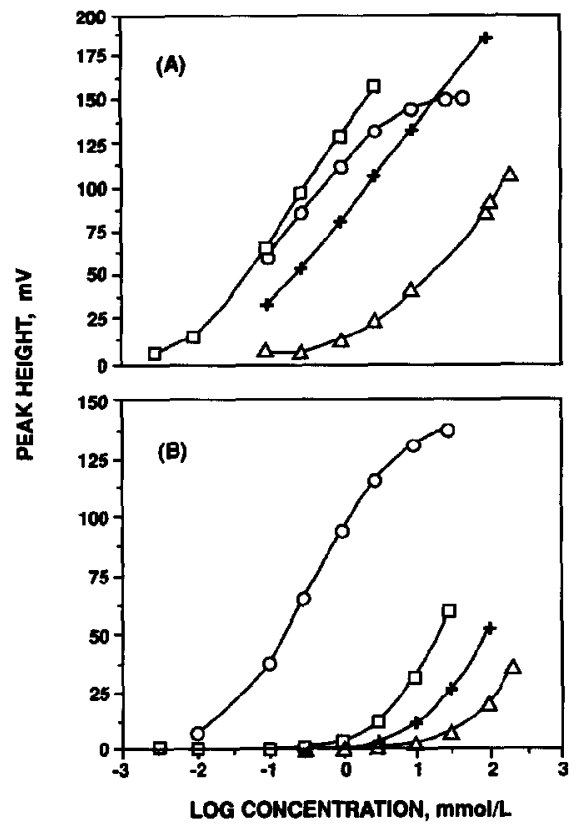

Fig 3 Response curves resulting from injectıons of $\mathrm{NH}_{4}^{+}(\square)$, $\mathrm{K}^{+}(+), \mathrm{Na}^{+}(\Delta)$, and L-glutamıne $(\mathrm{O})$ standards without (A) and with (B) Nafion ion-exchange tubing incorporated into the FIA system with immobilized glutaminase enzyme reactor

hancements in selectivtity are greater than 100 fold In the case of sodium, since the electrode already has relatively high selectivity over this cation $\left(\mathrm{e} \mathrm{g}, \mathrm{k}_{\mathrm{NH}_{4} / \mathrm{Na}}=10^{-3}\right.$ ), evaluation of the selectivity coefficient requires the injection of high concentrations of $\mathrm{NaCl}(\mathrm{e} \mathrm{g}, 02 \mathrm{M})$ to obtain a reasonable potentiometric response, and the removal efficiency at these very high sample cation concentrations is greatly reduced, hence there is less of an observed increase in apparent selectivity (see Table 2)

\section{TABLE 2}

Apparent selectivity coefficients for L-glutamıne over interferent cations, $k_{\text {gln } / \mathrm{J}}$, for integrated glutamine-FIA system ${ }^{\text {a b }}$

\begin{tabular}{llll}
\hline & $k_{\mathrm{gln} / \mathrm{NH}_{4}^{+}}$ & $k_{\mathrm{gln} / \mathrm{K}^{+}}$ & $k_{\mathrm{gln} / \mathrm{Na}^{+}}$ \\
\hline PTFE dummy tubing & 12 & $25 \times 10^{-1}$ & $31 \times 10^{-3}$ \\
Nafion tubing & $77 \times 10^{-3}$ & $19 \times 10^{-3}$ & $50 \times 10^{-4}$
\end{tabular}

\footnotetext{
aeasured at potentiometric response to $01 \mathrm{mM}$ glutamine standard in water ${ }^{b}$ Calculated using fixed potential-separate solution method [22]
} 


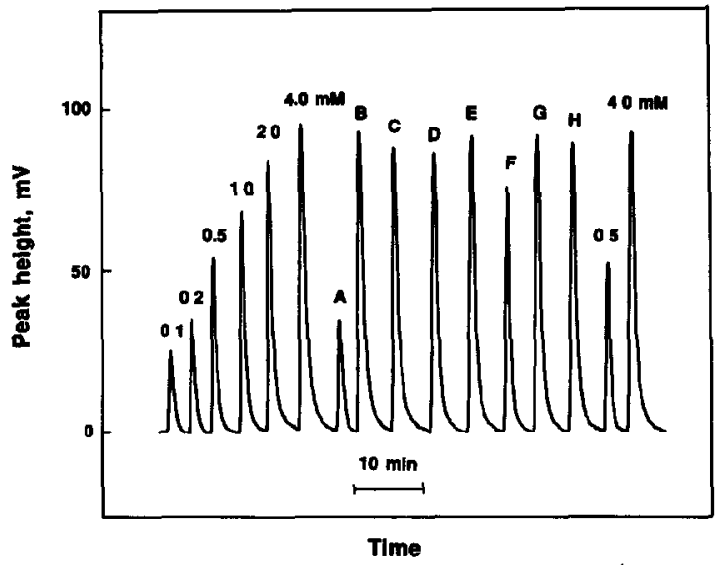

Fig 4 Typical strip-chart recording for calibration (standards 0 1-4 $0 \mathrm{mM}$ ) and measurement (media samples $\mathrm{A}-\mathrm{H}$ ) of L-glutamine in bioreactor media using new in-lıne Nafion/FIA biosensıng system

The analytical utility of the proposed approach was evaluated by determining L-glutamine levels in hybridoma bioreactor media samples This measurement is becoming increasingly important in the biutechnolugy field since it is now known that L-glutamine and glucose are the sole sources of energy for growth and monoclonal antibody production by hybridoma cells [23] Such medıa samples normally contain levels of endogenous ammonium lons that can approach the concentration of L-glutamine, and without correction and/or elimination, the background ammonium in the sample would cause positive errors in the measurement of L-glutamine [5,6,24] when using the highly selective glutaminase enzymatic approach Fig 4 shows a typical strip-chart recording for the calibration and measurement of Lglutamine in media samples To avoid matrix effects, L-glutamine standards were prepared in a glutamine-free media Resultıng calıbration curves (peak height in $\mathrm{mV}$ vs logarithm of $\mathrm{L}$ glutamine concentration) are linear over the range of 02-40 mM L-glutamine with slopes of 50-55 $\mathrm{mV}$ per decade (not shown) Determination of L-glutamine in 22 media samples by the proposed Nafion-based FIA system correlated well with a widely used LC method [20] [FIA $=112$ (LC) $009, r^{2}=096$, standard error of slope $=005$, standard error of $y$ (est $)=026$ ] It should be noted that the LC method requires sample pretreatment (derivatization) and at least 15-20 min to obtain a single result The new FIA approach enables direct injection of the media samples with a sample throughput of at least 20 samples per $h$

While the approach described herein is potentially applicable for the quantitative measurement of many other substrates which can be converted to ammonia / ammonium by suitable enzymes, the concept is not completely generic Indeed, substrates which are cationic under the operating conditions of the FIA system, or possess no charged sites at all ( $\mathrm{g}$, urea), will be capable of diffusing through the wall of the Nafion tubing, thus reducing the analyte concentration in the sample carrier stream that passes into the immobilızed enzyme/electrode detector portion of the system On the other hand, species that are an1onic are repelled by the fixed negative charged sites of the Nafion and remain at their original concentrations in the sample stream One surprising aspect of this work was the fact that zwitterionic species, such a L-glutamine, apparently do not permeate the walls of the Nafion tubing ( $\mathrm{e}$, isoelectric point for glutamine is $\mathrm{pH} 5$ 5) This fact was confirmed by comparing the overall response of the FIA system to injected L-glutamine standards with and without the Nafion tubing in place (e g, Fig 3) Although it is not yet clear what factors (structurally related) influence the permeability of such zwitterionic species through Nafion, further studies are underway to determine whether other zwitterionic substrates (e $\mathrm{g}$, phenylalanıne) behave sımilarly and, if so, to apply this new FIA approach in conjunction with appropriate immobilized enzymes, for the measurement of these biologically important molecules in complex samples

This work was supported by a grant from the National Science Foundation (BCS-9009389)

\section{REFERENCES}

1 International Union of Biochemistry, Enzyme Nomenclature, Academic Press, New York, 1978 
2 G G Gulbault, Handbook of Enzymatic Methods of Analysıs, Marcel Dekker, New York, 1976

3 Y M Fraticellı and ME Meyerhoff, Anal Chem, 55 (1983) 359

4 M E Collison and M E Meyerhoff, Anal Chım Acta, 200 (1987) 61

5 S A Rosario, GS Cha, ME Meyerhoff and M Trojanowicz, Anal Chem, 62 (1990) 2418

6 W Matuszewskı, S A Rosarıo and ME Meyerhoff, Anal Chem, 63 (1991) 1906

7 M Mascinı, S Fortunatı, D Moscone and G Palleschı, Anal Chım Acta, 171 (1985) 175

8 K. Kuhara and E Yasukawa, Anal Chım Acta, 183 (1986) 75

9 S P Chen, S S Kuan and G G Gulbault, Clın Chım Acta, 171 (1985) 175

10 M Tabata, T Kıdo, M Totanı and M Murachı, Anal Biochem , 134 (1983) 44

11 K. Yasuda, H Miyagı, Y Hamada and Y Takata, Analyst, 109 (1984) 61

12 M Mascinı and G Palleschı, Anal Chım Acta, 136 (1982) 69

13 M E Meyerhoff and G A Rechnitz, Anal Chrm Acta, 85 (1976) 277
$14 \mathrm{H}$ Small, T Stevens and W Bauman, Anal Chem, 47 (1975) 1801

15 J G Tarter (Ed), Ion Chromatography, Dekker, New York, 1987

16 S W Downey and G M Hieftje, Anal Chım Acta, 143 (1983) 1

17 L J Galante and GM Hieftje, Anal Chem, 59 (1987) 2293

$18 \mathrm{M}$ Trojanowicz and ME Meyerhoff, Anal Chım Acta, $222(1989) 95$

19 G S Cha and M E Meyerhoff, Talanta, 36 (1989) 271

20 S S Seaver, Rapıd High Performance Liquid Chromatography Techniques for Monitoring Amino Acids in Culture Fluids, Marcel Dekker, New York, 1987

21 S Hartman, J Biol Chem, 243 (1968) 853

$22 \mathrm{~K}$. Umezawa and $\mathrm{Y}$ Umezawa, Selectivity Coefficients for Ion-Selective Electrodes, University of Tokyo Press, Tokyo, 1983

23 L J Reitzer, B M Wice and D Kennell, J Biol Chem, 254 (1979) 2669

24 S S Ozturk, ME Meyerhoff and B O Palsson, Biotechnol Tech, 3 (1989) 217 